\title{
Trying to Deteriorate an Attraction Effect: A Lesson for Challengers
}

\author{
MS. Eric Santosa \\ Faculty of Economics and Business, \\ Unisbank University, Semarang, Indonesia
}

DOI: https://doi.org/10.36941/ajis-2020-0131

\begin{abstract}
The study is designed to answer a question: Can competitors override the effect of attraction that a particular firm's product has been experiencing? The study demonstrates that sale promotions, particularly discount and rebate, could lead to the alteration of attitude. Data are analyzed by employing Amos 22.0 and SPSS 21.0. The findings are not far from the expectation, that after the promotion of the competitor's product, the attraction effect is no longer remaining. The customers' intention to buy the product promoted obviously increases. In addition, hypotheses relating with attraction effect and theory of planned behavior are supported.
\end{abstract}

Keywords: attraction effect, attitude, customer sale promotions, behavioral intention

\section{Introduction}

An attraction effect leads a particular dominating product will get advantage of becoming more attractive than before. It might happen when another product is positioned adjacent to the first in which its two attributes are inferior. The advantage of becoming more attractive also occurs when the dominating product is not only superior of two attributes, but also one attribute (asymmetrical dominance). The second product might come from competitors, but it is not impossible it might be intentionally launched by the first product's manufacturer.

It is commonly understood that a success of a particular product cannot be separated from the strategy employed. One of strategies might be utilized to increase sales is deliberately applying the attraction effect. When the inferior product is purposely introduced by a firm which the dominant is its own, it is inevitably will increase the dominant product (Santosa, 2009a). On the contrary, others will experience of sales reduction. How is the reaction of others, allowing that firm experiences an increasing sale? Or trying to stop? How?

Attraction effect firstly is introduced by Huber, Payne and Puto (1982), and Huber and Puto (1983). Later on, Ratneshwar, Shocker and Stewart (1987) and also Simonson (1989) proclaim that the attraction effect also occurs on asymmetrical dominance. Some studies support the result, such as Kardes et al. (1989), Simonson and Tversky (1992), Pan and Lehman (1993). Mishra et al. (1993), Lehman and Pan (1994), Sivakumar and Cherian (1995), Lianxi et al., (1996), Doyle et al. (1999), Kim and Hasher (2005), Maylor and Roberts (2007), Kohler (2007), Hedgcock and Rao (2009), Santosa (2009a; 2011), Won (2012), Howes et al. (2016), and Gluth et al. (2017), in which their results are similar. Though the studies proclaim that the attraction effect really increases the choice of the dominant product, the studies do not explore further the process of the choice itself.

One of customer decision making models is theory of planned behavior (Ajzen, 1991), which is an 
improvement of theory of reasoned action (Fishbein and Ajzen, 1975) (docplayer.net). The theory proclaims that a particular behavior can be predicted from behavioral intention, which is developed by attitude, subjective norm and perceived behavioral control. Some researches apply the theory on many areas, such as Jyh (1998), Okun and Sloane (2002), Martin and Kulinna (2004), Wiethoff (2004), Marrone (2005), Kouthouris and Spontis (2005), and Santosa (2008, 2009b, 2011, 2016a) (Santosa, 2016c). The results positively corroborate the theory.

Employing the theory Santosa (2015) carries out a study which investigates the influence of attraction effect to choice, particularly behavioral intention. The results show that attraction effect has a significant influence whether to attitude or subjective norm. It allows that the attraction effect directly influences the intention as well.

While the choice process is still in question when a disturbance exists, Hedgcock and Rao (2009) find that a decoy might alter the choice. A decoy is a new choice alternative which influences a decision making towards two initial choices (Herne, 1997; Wikipedia, 2013). Further, Santosa (2019a) denotes that affective response influences the choice process as well. As a consequence, a choice might be diverse when a disruption goes along.

One aim of consumer sales promotions is to persuade consumer to choose the product promoted. It varies from discount, banded pack, rebate, coupon sweepstakes, and premium to continuity programs (Santosa, 2016b). It is very common that they are designed thoroughly to attract consumers. By offering something beneficial frequently customers are interested to choose the product promoted. A question may arise, when attraction effect is working can promotions revises the choice into the product promoted? The answer is absolutely the purpose of this study. Some theoretically reviews are provided. An enlightenment of methods, analysis and findings are reported.

\section{Literature Review}

\subsection{Attraction Effect}

Huber, Payne, and Puto (1982) and Huber and Puto (1983) are researches that initially proclaimed the finding, which is called attraction effect. The finding afterwards was further investigated by Ratneshwar, Shocker, and Stewart (1987) (Santosa, 2009a). Respondents showed two different brands (A and B) that each had two attributes. They had to choose one of the two. Two weeks later they had to choose the same two products but with one new brand $(C)$. The new product was dominated by one of the original alternatives (B) but not by the other (A). Respondents tended to alter their choice. The addition of brand $C$ increased the attractiveness and choice probability of the now asymmetrically dominating alternative (brand B) (Santosa, 2009a). Huber and Puto (1983) extended this finding to include the addition of non-dominated alternatives that were relatively inferior compared to one of the two alternatives in the core set (Santosa, 2009a) (Figure 1).

The finding alters the regularity that says a new alternative will not draw more shares from originals. In other words, one could not increase the choice probability of product by adding another product in the set (Simonson, 1989). This finding also runs counter to the similarity effect, that is, the intuition that a new alternative will draw more from the similar alternatives than from the dissimilar alternatives (Pan and Lehman, 1993; Santosa, 2009a).

Further, Huber and Puto (1983) explored more studies of attraction effect. On their experiment the new alternative was only relatively inferior compared to one of the two alternatives in the core set (brand E). The finding also shows the alteration of choice (Santosa, 2009a). 


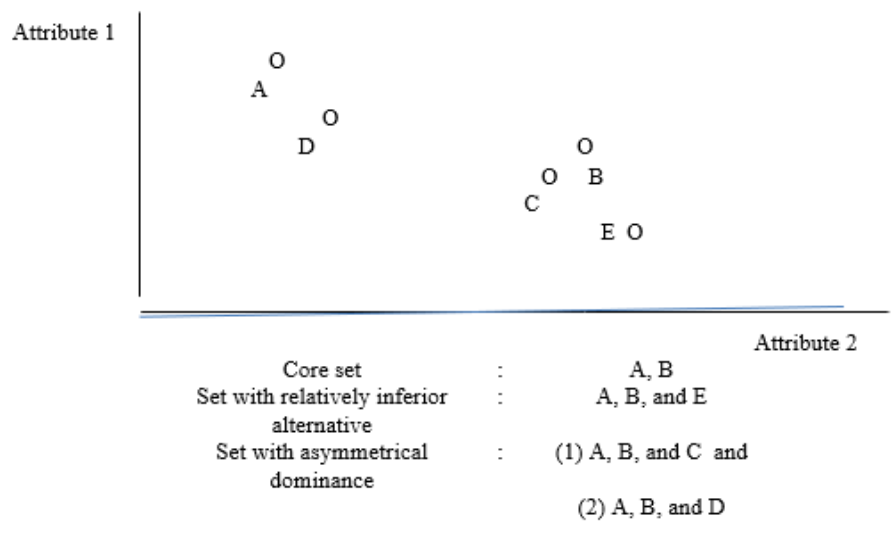

Figure 1. Attraction Effect

Source: Simonson, Itamar (1989). "Choice Based on Reason: The Case of Attraction and Compromise Effects”. Journal of Consumer Research. 16. September. p. 16o

The term of asymmetrical dominating product, relatively inferior product, and dominated product will be defined as follows. An asymmetrical dominating product is a product that in perceptual space of two given attributes has superiority, whether on one particular attribute or both, compared to other products (Pan and Lehman, 1993; Santosa, 2009a). A relatively inferior product is a product that in perceptual space of two given attributes has inferiority on only one attribute compared to a particular product. A dominated product is a product that in perceptual space of two given attributes has inferiority on one attribute or both compared to a particular product (Pan and Lehman, 1993; Santosa, 2009a).

\subsection{Theory of Planned Behavior (TPB)}

Theory of planned behavior (TPB) is firstly proclaimed by Ajzen (1991). It is actually a remedy of theory of reasoned action (TRA) which is introduced by Fishbein and Ajzen (1975) (ccse.net.org). The TRA signifies that particular behavior is preceded by intention, which can be predicted from attitude and subjective norm. To support the efficacy, Ajzen (1991) provides perceived behavior control which is a direct predictor of intention and indirect predictor of behavior.

The attitude usually consists of two components, i.e. outcome belief and outcome evaluation. The outcome belief relates to a tendency of particular outcome (Santosa, 2016c). For instance, there is a tendency that weight will be lessened by diet. Likewise, there is a tendency to get cancer by smoking. The power of the outcome belief is magnified by the outcome evaluation which significantly contributes to the form of behavioral belief. It is understandable that only a significant outcome wil virtually affect an individual's attitude (Santosa, 2016c).

The subjective norm appears as normative beliefs and motivation to comply. The normative belief is concerning with what other people want him/her to do something and his/her motivation to comply. As in attitude, the two factors should be multiplied to get greater power. A social pressure likely will be taken into account if appropriate to his/her motivation to comply (Santosa, 2016c).

The perceived behavioral control, basically, does not only influence the intention but also the behavior itself. The rationale is that holding intention constant, greater perceived control will increase the likelihood that enactment of the behavior will be successful. Furthermore, to the extent to which perceived behavioral control reflects actual control, perceived behavioral control will directly influence behavior. Therefore, it acts as both a proxy measure of actual control and a measure of confidence in one's ability (Santosa, 2016c).

As with the attitude and subjective norm constructs, Ajzen (1991) posits that control beliefs 
underpin perceived behavioral control. Control beliefs are the perceived frequency of facilitating or inhibiting factors multiplied by the power of those factors to inhibit/facilitate the behavior in question. Congruent with the other belief components in the TPB, it is the control beliefs that are salient at any one time which determine global perceptions of control (Santosa, 2016c).

The five variables afterward can be subsequently clarified as follows (Santosa, 2016c):

a. Behavior (B), is a certain action relating with certain object. A behavior usually always happens within a situational context in a particular time.

b. Behavioral Intention (BI), is a want correlating with self and action in the future. Some people may have an opinion that an intention is really a plan to do something concerning with a certain objective. A behavioral intention primarily is generated by a decision making process, which integrating factors such as attitude toward behavior and subjective norms, to evaluate alternatives which in turn choosing one of them. The behavioral intention varies of its power depending on the probability of doing something.

c. Attitude toward behavior or action (Ab or Aact), illustrating one's total evaluation to do something. The power and evaluation of a conspicuous conviction about a particular action consequence can be formulated as follows,

$$
\mathrm{Ab}=\sum_{\mathrm{i}=\mathbf{1}}^{\mathrm{n}} \text { bi ei }
$$

d. Subjective Norm, exemplifying one's perception about people surrounding think of what he/she should do. A normative belief is concerning with what other people want him/her to do something and his/her motivation to comply. The formula is as follows, $\mathrm{m}$

$\mathrm{SN}=\sum_{\mathrm{j}=\mathbf{1}} \mathrm{NB}_{1} \mathrm{MC} \mathbf{1}$

e. Perceived Behavioral Control (PBC), it refers to a degree where an individual considers that the creation of a particular behavior is under his/her control. He/she believes that a strong intention to behave will not arise when he/she is not sure that he/she has facilities or opportunities to do a particular behavior, although his/her attitude is favorable and the important people surround are in favor of him/her to do that. The formula is alike, o

$$
\mathrm{PBC}=\sum_{\mathrm{k}=\mathbf{1}} \mathrm{CBk} . \mathrm{PFk}
$$

\subsection{Consumer Sale Promotion}

Sale promotion is a marketing activity whether through media or non-media in a particular period of time which its aim is to induce sales, market demand and enhance agent's stocks (Santosa, 2016b). He further classifies the activity into (1) Price deals such as: discount, bonus/banded pack, refunds/rebates, coupon (2) Contest/Sweepstakes (3) Special Events: bazaar, show, fair etc. (4) Premiums, included direct premiums (traffic builders, door opener, referral premiums); mail premiums (5) Continuity programs and (6) Sampling.

\section{Formulating Hypotheses}

3.1 The Relation Between Attraction Effect (EA) and Attitude (Ab), and Between EA and Subjective Norm (SN).

The work of information and evaluation in a cognitive system are in line. They are in the same direction.An information might lead to meaning which in turn develops conviction (Peter and Olson, 2002). While whether information or evaluation has a great contribution in assessing a particular 
object, it is inevitably affected by the assessor's subjectivity. Thereby, an assessment toward a particular brand leads to a value in which a consumer believes that the particular brand has perceptive atribut in a particular product category (Pan and Lehmann, 1993). As a matter of fact, the perceptive atribut does not actually exist, it is abstract. Therefore, each consumer might have different perception (Sciffman and Wisenblit, 2015; Santosa, 2016c).

About the assessment itself, the consumer firstly classifies the information, incorporates with past experience, and later on comes to a conclusion which arises as a response (Peter and Olson, 2002). The subjective assessment occurs by means of a learning process relating with the atribut dimension, comparing a brand with others, and even reducing the amount of the atribut dimension which perceived just a few (Santosa, 2016c).

While a great quantity of brand and atribut of each product category makes consumers are not easy to integrate and analyze information, they simplify through subjective judgment or a belief toward a particular brand. The reason is the limitation of somebody's cognitive capacity (Bettman, 1979; Newell and Simon, 1972; Santosa, 2016c). In some studies of price, consumers compare one price to others resulting a perception of price. The price perception inevitably affects consumers in comprehending quality, value, and intention to buy (Dodds et al., 1991; Monroe and Petroshius, 1981).

The becoming more interesting of a product when an inferior product comes closer (attraction effect) obviously demonstrates the subjective judgment of consumers (Santosa, 2016c). While the subjective judgment will lead to an attitude creation through an integration of belief and evaluation, Santosa's study (2015) denotes that there is a significant influence of attraction effect to attitude. Thereby, a hypothesis can be formulated (Santosa, 2016c):

Hi: The atraction effect (EA) affects the attitude creation (Ab).

The subjective norm which developed through a normative belief and motivation to comply is apparently subjective. The more favorable of the subjective norm clearly is in accordance with the inner wants which actually always cares for other people's intention. The subjective judgment of the attraction effect will likely also affect the subjective norm when the other people's intention arises from a subjective judgment of the attraction effect (Santosa, 2016c). Further, Santosa's study (2015) indicates that there is a significant influence of attraction effect to subjective norm. As a consequence, a second hypothesis can be formed as follows:

$\mathrm{H}_{2}$ : The attraction effect (EA) affects the subjective norm (SN) creation

\subsection{The Relations between Sales Promotions and Attitude $(A b)$ and between Sales Promotions and Subjective Norm (SN) when promotions are carried out.}

Customer sales promotions commonly are designed as a well-informed marketing communication whether through mass media or non-mass media to generate customer's interest, which in turn will drive an establishment of intention (Santosa, 2016a). The creation of interest and intention is not on individuals, but hopefully has an effect on market as well. The growing of interest and intention itself obviously refers to attention. Therefore, not only individual but also market has attention of the product promoted. The activation of attention will inevitably lead to a generation of attitude as well, since attention is a component of attitude (Schiffman and Wisenblit, 2015).

Commonly, promotions offer something different than others, included such low price (discount, rebate, and coupon), hope (sweepstakes), and prize (premium), which arouse happiness. The good feeling actually cannot be split from individuals' affective system, which later on affects individuals' cognitive system (Schiffman and Wisenblit, 2015). The result is an appearance of knowledge, meaning and belief (Peter and Olson, 2002). In fact, both affective system and cognitive system belong to a process of developing individuals' attitude (Peter and Olson, 2002).

While Misra et al. (1993) suggest that there is an effect of motivation to attraction effect; Hedgcpck and Rao (2009) also state that a decoy will diminish an occurrence of asymmetric domination. Kim and Hasher (2005) recommend that there is a contribution of interest on alternative decision. Santosa (2019) finds that there is a significant influence of affective response to attitude. 
Thereby, some hypotheses could be formulated as follows:

$\mathrm{H}_{3}$ : Discount (Dis) influences attitude $(\mathrm{Ab})$

$\mathrm{H}_{4}$ : Discount (Dis) influences subjective norm (SN)

$\mathrm{H}_{5}$ : Rebate (Rab) influences attitude (Ab)

H6: Rebate (Rab) influences subjective norm (SN)

Correspondingly, similar hypotheses could be proposed as well as follows:

$\mathrm{H}_{7}$ : Coupon (Kup) affects attitude (Ab)

H8: Coupon (Kup) affects subjective norm (SN)

H9: Sweepstakes (Sweep) affects attitude (Ab)

H1o: Sweepstakes (Sweep) affects subjective norm (SN)

H11: Premium (Prem) affects attitude (Ab)

H12: Premium (Prem) affects subjective norm (SN)

3.3 The relations between the Attraction Effect (EA) and attitude (Ab) and between EA and Subjective Norms (SN) after sales promotions.

The employment of sales promotions leads the dominant product is going to be no longer attractive. It is assumed that the attraction effect will be ceased. Misra et al. (1993) find that an appealing offer of sales promotions will induce consumer's motivation to choose the promoted product. Kim and Hasher (2005) suggest the contribution of interest to alternative decision. Hedgcock and Rao (2009) find that a decoy will lessen an occurrence of asymmetric domination. Santosa (2019) finds a significant influence of affective response to attitude. Consequently, some hypotheses could be stated as follows:

H13: Sales promotions of the product promoted will deteriorate the influence of Attraction Effect (EA) to Attitude (Ab)

H14: Sales promotions of the product promoted will deteriorate the influence of Attraction Effect (EA) to Subjective Norm (SN).

\subsection{The Relation Between Attitude (Ab), Subjective Norms (SN), and Behavioral Intention (BI).}

The relations of whether $\mathrm{Ab}$ or SN with $\mathrm{BI}$ actually are in accordance with whether the theory of reasoned action (Fishbein \& Ajzen, 1975), or the theory of planned behavior (Ajzen, 1991) (hdl.handle.net). So, if hypothesized, it just wants to implement the theories to the case of the study. In addition, such studies (Jyh, 1998; Okun and Sloane, 2002; Martin and Kulinna, 2004; Wiethoff, 2004; Marrone,2005; Kouthouris \& Spontis, 2005; Santosa, (2008, 2009b, 2011, 2016a). also apply the theory of planned behavior to a particular case. Consequently, such hypotheses can be generated as well (Santosa, 2016c):

H15: The more favorable Attitude toward behavior (Ab), the more Behavioral Intention (BI) will be. H16: The more favorable Subjective Norm (SNB1), the more Behavioral Intention (BIB1) will be.

\section{Research Model}

Referring the hypotheses, a research model could be drawn as follows (see fig. 2).

\section{Methods}

Employing a convenience and judgment technique (Cooper and Schindler, 20o8), a sample is generated. Respondents are those who are interested to motorbikes particularly matic, whether own or not. They are asked to submit questionnaires soon. The questionnaires firstly are checked whether they are complete or not. 100 questionnaire forms are successfully admitted out of 102 forms (98\% response rate), which supposed meet the sample adequacy (Ghozali, 2008; Hair et al., 2019b) and liable to be further administered. The questionnaires operate a Likert scale, where each item has five alternatives; from 
completely agree to completely disagree. The instruments are scrutinized by confirmatory factor analysis and Cronbach's Alpha to indicate that they are valid and reliable. To analyze data Amos 22.o is operated.

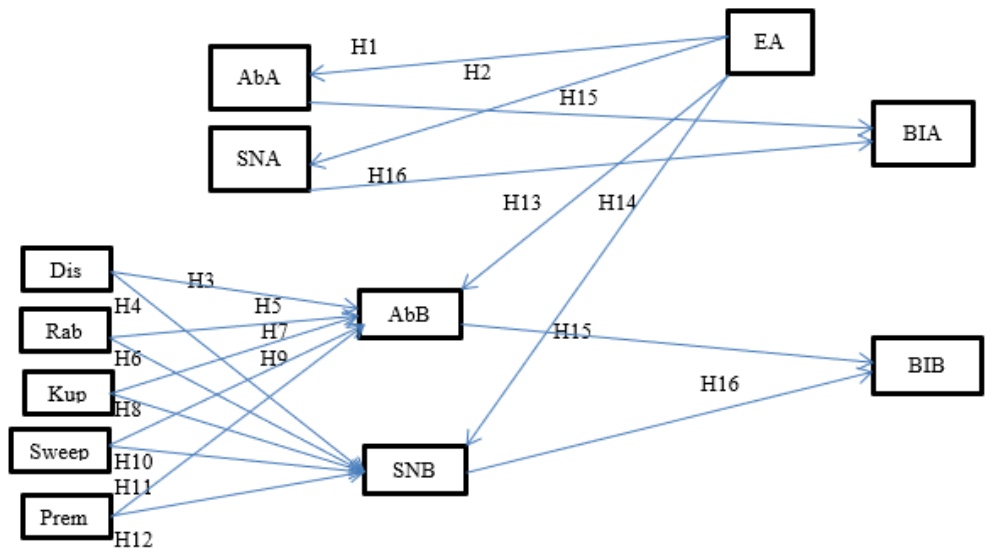

Note

EA : Attraction effect

AbA : Attitude before promotion

SNA : Subjective norm before promotion

BIA : Behavioral intention before promotion

Kup : Coupon

Dis : Discount

Sweep : Sweepstakes

Prem : Premium

Rab : Rebate

AbB : Attitude after promotion

SNB : Subjective norm after promotion

BIB : Behavioral intention after promotion

Figure 2. Research Model

\section{Analysis and Result}

\subsection{Test of Validity}

The confirmatory factor analysis produces output as follows: factor loading of indicators such as $\mathrm{Ab}$ i.e. $\mathrm{bA}, \mathrm{bB}$ and evA, evB; SN i.e. NBA, NBB and MCA, MCB; BI i.e. BIA, BIB is above the upper limit i.e. o.5 (Table 1). Thereby, all are valid (Ghozali, 2008) Meanwhile, factor loading of EA, Dis, Rab, Kup, Sweep, and Prem are not detected since the variables are only measured by one indicator.

Table 1. Factor Loading of b, ev, NB, MC, BI

\begin{tabular}{|c|c|c|c|}
\hline Indicator & Factor Loading & Cut-off & Criteria \\
\hline bA & 0.781 & 0.5 & Valid \\
bB & 0.833 & 0.5 & Valid \\
evA & 0.832 & 0.5 & Valid \\
evB & 0.840 & 0.5 & Valid \\
NBA & 0.756 & 0.5 & Valid \\
NBB & 0.874 & 0.5 & Valid \\
MCA & 0.816 & 0.5 & Valid \\
MCB & 0.862 & 0.5 & Valid \\
BIA & 0.750 & 0.5 & Valid \\
BIB & 0.864 & 0.5 & Valid \\
\hline
\end{tabular}

Source: Amos Output

\subsection{Test of Reliability}

The reliability of the instruments is measured by Cronbach's Alpha. The result shows as follows: 
Table 2. Cronbach.s Alpha of Items

\begin{tabular}{|l|c|c|c|}
\hline Indicator & Cronbach's Alpha & Cut-off & Criteria \\
\hline bA, evA & 0.850 & 0,6 & Reliable \\
bB, evB & 0.881 & 0,6 & Reliable \\
NBA, MCA & 0.808 & 0,6 & Reliable \\
NBB, MCB & 0.824 & 0,6 & Reliable \\
AbA, evA, BIA & 0.680 & 0,6 & Reliable \\
AbB, SNB, BIB & 0.656 & 0,6 & Reliable \\
\hline
\end{tabular}

Source: Amos Output

\subsection{Allowing a Goodness of Fit Model}

Indicators of the first model do not indicate a good performance (Table 3). It should be modified in accordance with modification indices. The modification leads to the second model (Figure 3). Its indicators approximately meet the criteria of goodness of fit, particularly Cmin/df, TLI and RMSEA (Table 3).

Table 3. The Indicators of the First and the Second Model

\begin{tabular}{|c|c|c|c|c|}
\hline Indicators & $\mathbf{1}^{\text {st }}$ Model's Scores & $2^{\text {nd }}$ Model's Scores & Threshold & Criteria the $2^{\text {nd }}$ Model \\
\hline Chi- sq/Prob & $661,948 / \mathrm{o}, 000$ & $251,310 / 0,000$ & $65,24722 / \mathrm{p}>0.001$ & Not Meet \\
\hline $\mathrm{Cmin} / \mathrm{df}$ & 4,443 & 1,821 & $\leq 5$ & Meet \\
\hline GFI & 0,695 & 0,829 & High & Not Meet \\
\hline AGFI & 0,570 & 0,740 & $\geq 0,9$ & Not Meet \\
\hline TLI & 0,667 & 0,933 & $\geq 0,9$ & Meet \\
\hline RMSEA & 0,179 & 0,087 & 0,05 s.d o,o8 & Meet \\
\hline
\end{tabular}

Source: Data analysis

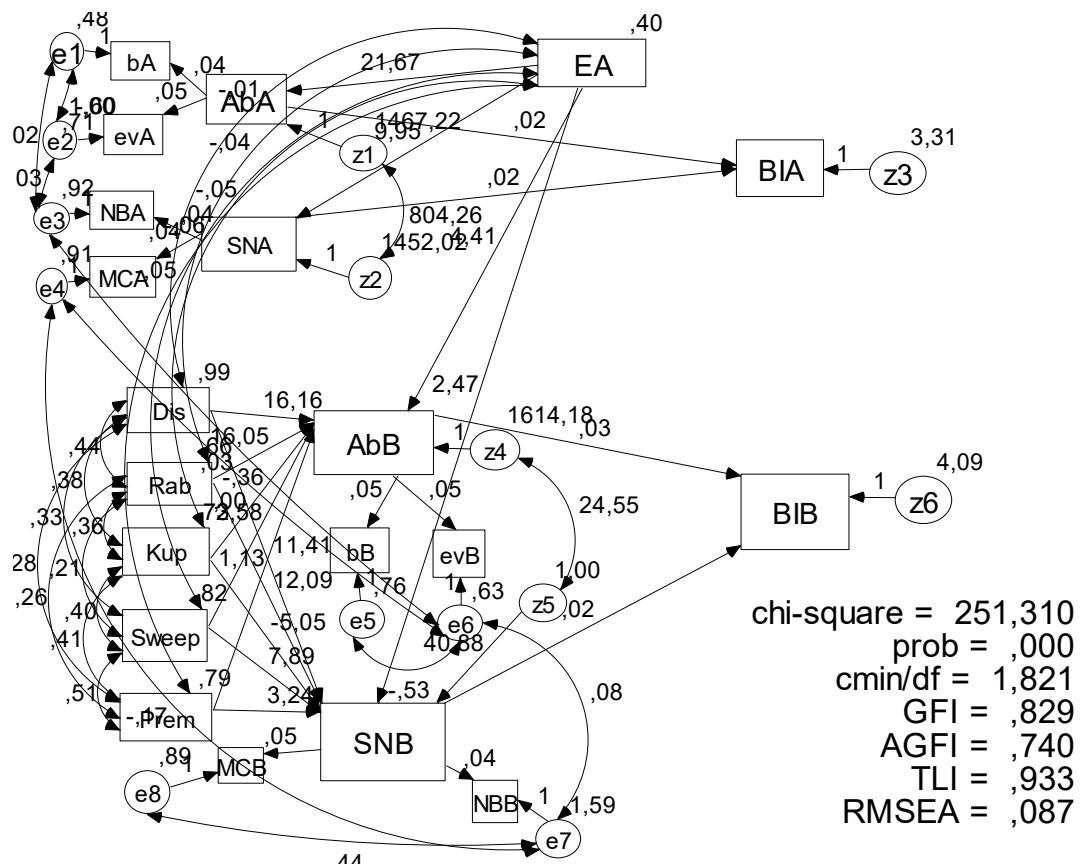

Figure 3. The Second Model 


\subsection{Test oh Hypotheses}

The influence of exogenous construct to endogenous construct is demonstrated at Table 4 . It shows that the influence of EA to AbA is significant $(\mathrm{p}=0.000)$. Likewise, the influence of EA to SN $(\mathrm{p}=$ $\left.0.068^{*}\right)$. Therefore, $\mathrm{H}_{1}$ and $\mathrm{H}_{2}$ are empirically supported.

The influences of Dis to $\mathrm{Ab}(\mathrm{p}=0.006)$ is significant. Likewise, Rab $\left(\left(\mathrm{p}=0,065^{*}\right)\right.$. On the contrary, the influence of $\operatorname{Kup}(\mathrm{p}=0,739)$, sweepstakes $(\mathrm{p}=0,752)$, and premium $(\mathrm{p}=0,752)$ are not significant. The influence of discount, rebate, coupon, sweepstakes, or premium to subjective norm is not significant. Thereby, $\mathrm{H}_{3}$ and $\mathrm{H}_{5}$ are empirically supported, while $\mathrm{H}_{4}, \mathrm{H} 6, \mathrm{H}_{7}, \mathrm{H} 8, \mathrm{H}_{9}, \mathrm{H}_{10}, \mathrm{H}_{11}$ and $\mathrm{H}_{12}$ are not (Table 4).

The power of sale promotion is also revealed when the attraction effect is no longer control of forming attitude and subjective norm. EA's influence to AbB ( $\mathrm{p}=0.0295)$ and SNB ( $\mathrm{p}=0.655)$ are not significant. Thus, $\mathrm{H}_{13}$ and $\mathrm{H}_{14}$ are empirically supported (Table 4). The influence of whether attitude or subjective norm to behavioral intention is significant. The AbA's influence $(\mathrm{p}=0.006)$ and SNB's influence $(\mathrm{p}=0.000)$ to BIA are significant. So, $\mathrm{H}_{15}$ and $\mathrm{H}_{16}$ are empirically supported (Table 4 ).

Table 4. Regression Weight among Variables

\begin{tabular}{|c|c|c|c|c|c|c|c|}
\hline & & & Estimate & S.E. & C.R. & $\mathrm{P}$ & Label \\
\hline AbA & $<---$ & EA & 20,048 & 4,895 & 4,095 & $* * *$ & par_5 \\
\hline $\mathrm{AbB}$ & $<---$ & Dis & 11,749 & 4,282 & 2,744 & , oo6 & par_8 \\
\hline AbB & $<---$ & Rab & 9,975 & 5,401 & 1,847 & , 065 & par_9 \\
\hline $\mathrm{AbB}$ & $<---$ & Kup & 1,789 & 5,363 & ,334 & ,739 & par_10 \\
\hline $\mathrm{AbB}$ & $<---$ & Sweep & 1,592 & 5,048 & ,315 & ,752 & par_11 \\
\hline $\mathrm{AbB}$ & $<---$ & Prem & 1,637 & 5,174 &, 316 & ,752 & par_12 \\
\hline SNB & $<---$ & Dis & 3,803 & 3,855 & ,987 &, 324 & par_13 \\
\hline SNB & $<---$ & Rab & 7,903 & 5,005 & 1,579 & ,114 & par_14 \\
\hline SNB & $<---$ & Kup & $-4,132$ & 4,676 &,- 884 & ,377 & par_15 \\
\hline SNB & $<---$ & Sweep & 5,644 & 4,541 & 1,243 & ,214 & par_16 \\
\hline SNB & $<---$ & Prem & 3,379 & 4,451 & ,759 & , 448 & par_17 \\
\hline AbB & $<---$ & EA & 5,622 & 5,370 & 1,047 & ,295 & par_22 \\
\hline SNA & $<---$ & EA & 8,901 & 4,884 & 1,822 & o68 & par_23 \\
\hline SNB & $<---$ & EA & 2,079 & 4,647 & , 447 & ,655 & par_68 \\
\hline BIA & $<---$ & AbA & ,014 &, 005 & 2,744 & , oo6 & par_6 \\
\hline BIA & $<---$ & SNA & ,034 & , oo6 & 5,990 & $* * *$ & par_7 \\
\hline BIB & $<---$ & SNB & , 022 & , 005 & 4,017 & $* * *$ & par_20 \\
\hline BIB & $<---$ & $\mathrm{AbB}$ & ,025 & ,005 & 5,003 & $* * *$ & par_21 \\
\hline
\end{tabular}

Source: Amos Output

\section{Discussion}

The empirically supported of $\mathrm{H}_{1}$ and $\mathrm{H}_{2}$ indicates that the attraction effect really affects the attitude and subjective norm creation. The finding is in line with Santosa's findings $(2015,2019)$. While it corresponds of such similar study or even a new finding if no such exploration before, it should be appreciated as a new significant fact into theoretical development. The subjective judgment which generated by the effect of attraction, in turn will develop attitude, Further, each consumer' subjective 
judgment will consent a development of collective attitude as an effect of consumer compliance surround. While it needs support, it is desired to others particularly science communities to explore further.

The empirically supported of $\mathrm{H}_{13}$ and $\mathrm{H}_{14}$ indicates that after sale promotion of the competitor, the attraction affect has no longer power of attitude and subjective norm. The dominant product that is the product that becomes more attractive as the clout of the attraction effect, likely has not enough power to persuade consumers to choose. Consumers seemingly prefer the product promoted. It obviously refers to Santosa (2019) that affective response affects consumer's attitude. The attractive offer allows consumer to develop favorable attitude toward the product promoted. The finding tends to resemble the study of Misra et al. (1993) in which the attractive offers motivate consumers to choose the product promoted. The finding also looks like the study of Hedgcock and Rao (2009) about an excitement that might deteriorate the attraction effect. The finding is also similar with the study of Kim and Hasher (2005) who suggest that there is an influence of interest to an alternative choice.

The empirically supported of $\mathrm{H}_{15}$ and $\mathrm{H}_{16}$ denotes that the influence of attitude and subjective norm to behavioral intention is in accordance with the theory of planned behavior. It is obvious that both are good predictors of behavioral intention. The finding is absolutely appropriate with studies of Jyh (1998), Okun and Sloane (2002), Martin and Kulinna (2004), Wiethoff (2004), Marrone (2005 Kouthouris and Spontis (2005), and Santosa (2008, 2009b, 2011, 2016a).

\section{Conclusion}

\subsection{Conclusion}

The study can be inferred into three categories. Firstly, the influence of attraction effect, when it works and not. Secondly, sale promotion influences attitude and subjective norm. Thirdly the TPB is supported. The first produces three important findings that are, the attraction effect affects the consumer's attitude, the attraction effect affects the subjective norm, and after sale promotion the attraction effect does not affect attitude and subjective norm any more.

The second generates findings relating with the influence of sale promotion to whether attitude or subjective norm. Those that have significant affect to attitude are only discount and rebate. No variant of sale promotion has a significant effect to subjective norm.

The third denotes to the influence of whether attribute or subjective norm to behavioral intention. It looks like that the good predictors of behavioral intention corroborate the theory of planned behavior.

\subsection{Managerial Implication}

These findings enlarge and give details of the situation consumers meet when making a choice. It is likely recognized that the TPB works well under normal condition, that is investigating someone in doing something, in which competitors are absent. While the situation might change, when competitors get in, the decision making thereby, is not simple. It is obviously known that the TPB initially developed not only for marketing. However, when marketers talk about market, they should pay attention to competitors. In other words, when they need to know the reason of doing something, i.e. choosing a particular product/brand, they should inevitably take competitors into account.

The attraction effect might occur unintentionally, but it might on purpose. Both has an effect on choice, though indirectly through attitude and subjective norm creation. This is in accordance with the findings that the effect does not directly influence the consumers' intention. Under such condition, the choice might change when the products in the market also change, particularly when the composition of products which develop the attraction effect is deliberately modified. As a consequence, understanding consumers in making a choice applying the TPB let marketers unavoidably also recognize products in the market. 
The power of attraction effect is not everlasting. Competitor' sale promotion can deteriorate the effect. Actually, two parties are involved, firstly, a firm who own particular product getting attraction effect. Secondly, a firm executes sales promotion. Getting aware of the work of attraction effect obviously needs time. However, a challenger should be always conscious by carefully noticing the movement in the market. A rival's price list and product specification are very useful to investigate whether attraction effect will happen or not. When it is detected will occur the challenger should arrange a discount and rebate strategy soon to counter the effect.

\section{References}

Ajzen, I. (1991). The Theory of Planned Behavior. Organizational Behavior and Human Decision Processes. 50. pp. 179-211.

Bettman, J.R. (1979). An Information Processing Theory of Consumer Choice. Reading, MA: Addison-Wesley.

ccse.net.org

Cooper, D.R. and Schindler, P.S. (2008). Business Research Methods. Boston: McGraw-Hill/Irwin.

docplayer.net

Dodds, W.B, Monroe, K.B, and Grewal, D. (1991). Effect of Price, Brand, and Store Information on Buyer's Product Evaluations. Journal of Consumer Re-search. 5 (September). pp. 138-142.

Doyle, J, O'Connor,D, G. Reynolds, G, and Bottomley, G.P. (1999). The Robustness of the Asymmetrically Dominated Effect: Buying Frames, Phantom Alternatives, and In-Store Purchases, Psychology E Marketing 16(3), 225-243,

Fishbein, M and Ajzen, I. (1975). Belief, Attitude, Intention, and Behavior: An Introduction to Theory and Research. Reading, MA: Adisson-Wesley.

Gluth, S, Jared M.H, and Jörg R. (2017). The Attraction Effect Modulates Reward Prediction Errors and Intertemporal Choices. The Journal of Neuroscience (2017), doi: 10.1523/jneurosci.2532-16.2017.

Ghozali, I. (2008). Model Persamaan Struktural: Konsep dan Aplikasi dengan Program Amos Ver 16.o. Semarang: BP Undip.

Hair, JF Jr, Black, WC, Babin, BJ, Anderson, RE. (2019b). Multivariate Data Analysis. 8th ed. Hampshire, UK: Congage.

Hedgcock, W and Rao, A.R. (2009), Trade-Off Aversion as an Explanation for the Attraction Effect: A Functional Magnetic Resonance Imaging Study. Journal of Marketing Research. Vol 46, No 1, February 2009.

Herne, K. (1997). Decoy alternatives in policy choices: Asymmetric domination and compromise effects. European Journal of Political Economy. vol 13, issue 3, September. pp 575-589.

Howes A, Warren P.A and Farmer G.E. (2016). Why Contextual Preference Reversals Maximiza Expected Value Psychological Review. July. 123 (4). 368-391.

Huber, J and Puto C. (1983). Market Boundaries and Product Choice: Illustrating Attraction and Substitution Effects. Journal of Consumer Research. 10. June. pp. 31-44.

Huber, J. Payne J.W and Puto, C. (1982). Adding Asymmetrically Dominated Alternatives: Violations of Regularity and Similarity Hypothesis. Journal of Consumer Research. 9. June. pp. 90-98.

Jyh,S.C, (1998). The Effect of Attitude, Subjective Norm, and Perceived Behavioral Control on Consumers' Purchase Intentions: The Moderating Effects of Product Knowledge and Attention to Social Comparison Information. Proc.Natl. Sci. Counc. ROC (C). 9.2. pp 298-308.

Kardes, F.R, Herr, P.M. and Marlino, D. (1989). Some New Light on Substitution and Attraction Effects. Advances in Consumer Research. 16. pp. 203-208.

Kim, S and Hasher L. (2005). The Attraction Effect in Decision Making: Superior Performance by Older Adults. QJ Exp Psychol A. 2005 January; 58.(1): 120-133.

Kohler, W.R. (2007). Why does Context Matter? Attraction Effects and Binary Comparisons. Working Paper No. 330. Zurich, Switzerland: Institute for Empirical Research in Economics, University of Zurich.

Kouthouris, CH. and Spontis, A. (2005). Outdoor Recreation Participation: An Application of the Theory of Planned Behavior. The Sport Journal, Vol. 8, Number 3, United States Sport Academy.

Lehmann, D.R. and Pan, Y. (1994). Context Effects, New Brand Entry, and Consideration Sets. Journal of Marketing Research. XXXI. August. pp. 364-374.

Lianxi Z, Kim C, and Laroche M (1996). Decision Processes of the Attraction Effect: a Theoretical Analysis and Some Preliminary Evidence, in NA - Advances in Consumer Research Vol. 23, eds. Kim P. Corfman and John G. Lynch Jr., Provo, UT: Association for Consumer Research, 218-224. 
Kouthouris, C.H and Spontis, A. (2005). Outdoor Recreation Participation: An Application of the Theory of Planned Behavior. The Sport Journal, Vol. 8, Number 3, United States Sport Academy.

Marrone, S.R. (2005). Attitudes, Subjective Norms, and Perceived Behavioral Control: Critical Care Nurses' Intentions to Provide Culturally Congruent Care to Arab Muslims. Research Report. Columbia University Teachers College (unpublished).

Martin, J.J. and Kulinna, P.H. (2004). Self-Efficacy Theory and Theory of Planned Behavior: Teaching Physically Active Physical Education Classes. Research Quarterly for Exercise and Sport, Vol. 75 No. 3, 288-297.

Maylor, E.A, and Roberts. M.A.J. (2007). Similarity and Attraction Effects in Episodic Memory. Cognition. 105. (3). December, pp. 715-723.

Mishra S, Umesh U.N, and Stem D.E Jr. (1993). Antecedents of the attraction effect: An information-processing approach. Journal of Marketing Research. 30:331-349.

Monroe, K.B and Petroshius, S.M. (1981). Buyer's Perception of Price: An Update of the Evidence. In Perspectives in Consumer Behavior. Ed Harold H Kassarjian and Thomas S Robertson, Glenview. IL: Scott, Foresman. pp. 43-55.

Newell, A and Simon, H.A. (1972). Human Problem Solving. Englewood Cliffs, NJ: Prentice-Hall.

Okun, M.A. and Sloane, E.S. (2002). Application of Planned Behavior Theory to Predicting Volunteer Enrollment by College Students in a Campus-Based Program. Social Behavior and Personality. Tempe: Arizona State University.

Pan, Y. and Lehmann, D.R. (1993). The Influence of New Brand Entry on Subjective Brand Judgments. Journal of Consumer Research. 20. June. pp. 76-86.

Peter, J. and Olson, J.C. (2002). Consumer Behavior and Marketing Strategy. $6^{\text {th }}$ Ed. New York: McGraw-Hill Book Company.

Ratneshwar, S, Shocker, A.D and Stewart, D.W. (1987). Toward Understanding the Attraction Effect: The Implication of Product Stimulus Meaningfulness and Familiarity. Journal of Consumer Research. 13. March. pp. 520-533.

Santosa, M.S.E. (2008). How People Elect Candidates: The Analyze of Attitude, Subjective Norm, and Intention to Behavior- The Case of Pilgub in Central Java. Optimal, 6, (1), October.

Santosa, M.S.E. (2009a). Factors Affecting Choice in a Multi-stage Model: The Influence of Saliency and Similarity on Retrieval Set and The Implication of Context Effect on Consideration Set. Gama International Journal of Business (IJB) UGM Vol 11, No 3, edisi Sept-Des 2009.

Santosa, M.S.E. (2009b). Understanding People in Electing Jusuf Kalla as a Candidate on Presidenti\al Election 20o9: using the Theory of Planned Behavior. Equilibrium, Vol III, No 2, Oktober 2009.

Santosa, M.S.E. (2011). Understanding Customers' Behavior to Choicing 'Lembah Ngosit' Restaurant Using the Theory of Planned Behavior. Equilibrium, Vol V, Ed 1 Ap 2011 pp. 40-55.

Santosa, M.S.E. (2015). Attration Effect on Consumer's Decision Making. International Journal of Applied Business and Economic Research (IJABER) 13. (2). 2015. Part 1. Pp. 1759-1780.

Santosa, M.S.E. (2016a). Terbentuknya Sikap dan Norma Subjektif Pelanggan dari Adanya Ketidakpuasan dan Citra Provider yang Buruk serta Dampaknya Terhadap Niat Pelanggan untuk Switch- Kasus Pencurian Pulsa. Equilibrium, Vol X.1.April. 2016, pp. 1-23.

Santosa, M.S.E. (2016b). Strategi Pemasaran Internasional. Semarang: Unisbank.

Santosa, M.S.E. (2016c). Compromise Effect on Consumer's Decision Making. Journal of Indonesian Economy and Business, JIEB UGM, vol 31 No 3 Sep 2016. pp. 325-344.

Santosa, M.S.E. (2019). Affective Response and Attraction Effect on Consumer's Intention to Buy. Economics, Law and Policy. Vol. 2, No. 1, 2019. 90-112.

Schiffman, L.G. and Wisenblit, J.L. (2015). Consumer Behaviour, Global Edition. Pearson Education Limited.

Simonson, I and Tversky, A. (1992). Choice in Context: Tradeoff Contrast and Extremeness Aversion. Journal of Marketing Research. 29. August. 281-295.

Simonson, I. (1989). Choice Based on Reasons: The Case of Attraction and Compromise Effects. Journal of Consumer Research. 7. September. pp. 158-174.

Sivakumar, K and Cherian, J. (1995). Role of Product Entry and Exit on the Attraction Effect. Marketing Letters, 6. (1). January, pp. 45-51.

Wiethoff, C. (2004) Motivation to Learn and Diversity Training: Application of the Theory of Planned Behavior. Human Resource Development Quarterly, Vol. 15 No. 3.

Wikipedia. (2013). Decoy Effect. Available at https://en.wikipedia.org/wiki/Decoy_effect. Accessed at Juni 2016.

Won, E.J.S. (2012). A Theoretical Investigation on the Attraction Effect Using the Elimination by Aspects Model Incorporating Higher Preference for Shared Features. Jourmal of Mathematical Psychology. October. 56 (5). 386-391. 